\title{
Aversive and Appetitive Events Evoke the Release of Corticotropin- Releasing Hormone and Bombesin-Like Peptides at the Central Nucleus of the Amygdala
}

\author{
Zul Merali, ${ }^{1,2}$ Judy McIntosh,, ${ }^{1}$ Pamela Kent, ${ }^{1}$ David Michaud, ${ }^{1}$ and Hymie Anisman ${ }^{3}$ \\ ${ }^{1}$ School of Psychology and ${ }^{2}$ Department of Cellular and Molecular Medicine, University of Ottawa, Ottawa, Ontario, \\ Canada K1N 6N5, and 3/nstitute of Neuroscience, Carleton University, Ottawa, Ontario, Canada K1S 5B6
}

There is wide agreement that corticotropin-releasing hormone $(\mathrm{CRH})$ systems within the brain are activated by stressful stimuli. There is also mounting evidence for the role of bombesin (BN)-like peptides in the mediation of the stress response. To date, however, the extent to which other stimuli increase the activity of these peptidergic systems has received little attention. In the present investigation we validated and used in vivo microdialysis sampling followed by ex vivo radioimmunoassays to monitor the release of $\mathrm{CRH}$ and $\mathrm{BN}$-like peptides during appetitive (food intake) and stressful (restraint) events. It is demonstrated for the first time that the in vivo release of $\mathrm{CRH}$ and BN-like peptides at the central nucleus of the amygdala was markedly increased by both stressor exposure and food ingestion. In fact, the meal-elicited rise of $\mathrm{CRH}$ release was as great as that associated with 20 min of restraint stress. Paral-

There is considerable evidence suggesting that corticotropinreleasing hormone $(\mathrm{CRH})$, a hypophysiotropic peptide comprising 41 amino acids (Vale et al., 1981), plays a fundamental role in stress reactivity. In particular, stressors reliably enhance the expression of CRH mRNA in hypothalamus (Bartanusz et al., 1993; Kiss et al., 1996; Kovács and Sawchenko, 1996; Sawchenko et al., 1996; Turnbull and Rivier, 1997), and intracerebroventricular administration of CRH elicits a constellation of behavioral, physiological, and endocrinological changes similar to those produced by stressors (Dunn and Berridge, 1990). Conversely, CRH antagonists attenuate the behavioral effects of CRH, as well as those elicited by stressors (Gray, 1991; Heilig et al., 1994). In addition to hypothalamic $\mathrm{CRH}$, it seems that central amygdaloid $\mathrm{CRH}$ changes are also intricately involved in orchestrating the response to stressors. In this respect, amygdaloid $\mathrm{CRH}$ manipulations predictably affect behaviors indicative of anxiety (Dunn and Berridge, 1990; Swiergiel et al., 1993; Kalin et al., 1994), although these effects may be more closely aligned with a fear response than nonspecific anxiety (Lee and Davis, 1997). Moreover, stressors have been shown to affect CRH mRNA levels and the levels of CRH within the amygdala (Pich et al., 1995). In this respect, various aversive conditions (such as withdrawal from alcohol, cocaine, or cannaboids) influence the levels and/or turnover of

\footnotetext{
Received Nov. 24, 1997; revised March 17, 1998; accepted March 31, 1998.

This research was supported by grants from the Medical Research Council and the National Science and Engineering Research Council of Canada.

Correspondence should be addressed to Dr. Zul Merali, School of Psychology, University of Ottawa, 11 Marie Curie, Room 204, Ottawa, Ontario, Canada, K1N 6N5. E-mail address: merali@uottawa.ca

Copyright (ㄷ) 1998 Society for Neuroscience $\quad 0270-6474 / 98 / 184758-09 \$ 05.00 / 0$
}

leling these findings, circulating ACTH and corticosterone levels were also increased in response to both food intake and restraint. Contrary to the current views, these results indicate that either food ingestion is interpreted as a "stressful" event by certain neural circuits involving the central amygdala or that the $\mathrm{CRH}$ - and $\mathrm{BN}$-related peptidergic systems may serve a much broader role than previously envisioned. Rather than evoking feelings of fear and anxiety, these systems may serve to draw attention to events or cues of biological significance, such as those associated with food availability as well as those posing a threat to survival.

Key words: corticotropin-releasing factor; gastrin-releasing peptide; neuromedin C; restraint stress; reward; feeding; eating disorders; stress

CRH at the central nucleus of the amygdala (Pich et al., 1995; Rodríguez de Fonseca et al., 1997).

The hypothalamo-pituitary axis (HPA) activation associated with stressors is an exceedingly robust phenomenon, so much so that glucocorticoid changes have been taken to reflect the presence of stressors. Contrary to this dogma, however, there is reason to believe that alterations of HPA activity may be influenced by appetitive stimuli, just as aversive events elicit such effects. For example, Dallman et al. (1995), Schwartz et al. (1995), and Shiraishi et al. (1984) have reported that the HPA responsiveness to stressors was influenced by whether the animals were food-deprived or sated. Furthermore, food consumption itself, as well as other rewarding stimuli, promote glucocorticoid secretion (Piazza and LeMoal, 1997). In the case of humans, cortisol response to food occurs before the food is actually absorbed from the gastrointestinal tract (Follenius et al., 1982; Al-Damluji et al., 1987; Karbonits et al., 1996). There is electrophysiological evidence supporting the view that information processing involving the cortex-amygdala-lateral hypothalamus contributes to the control of feeding behaviors, as well. In particular, it was demonstrated that some amygdala neurons responded to cues associated with food and that the degree of responsiveness varied with the apparent affective significance of the stimulus (Fukuda and Ono, 1993). The suggestion has indeed been offered that the amygdala contributes to the processes by which sensory stimuli gain motivational and emotional significance (Jones and Mishkin, 1972; Spiegler and Mishkin, 1981; Gaffan et al., 1988; Zola-Morgan et al., 1991). In effect, neurons of the central amygdala may react to the salience or significance of emotional stimuli rather than simply the negative or positive attributes of these stimuli. 
Like CRH, the bombesin family of peptides may be part of a constellation of responses to both stressors and feeding. For instance, endogenous levels of BN-like peptides in several brain regions vary during the course of a meal (Merali and Kateb, 1993; Plamondon and Merali, 1997), and exogenous administration of BN suppresses food intake (Gibbs, 1985; Merali et al., 1993). Interestingly, BN administration markedly elevates circulating ACTH levels, and this effect can be blocked by pretreatment with a CRH antagonist (Merali et al., 1994). Moreover, stressors influence BN-like immunoreactivity in several brain regions, particularly the hypothalamus (Kent et al., 1998). Thus, there is reason to believe that $\mathrm{BN}$-like peptides modulate the HPA response to both appetitive and aversive stimuli.

In the present investigation we demonstrate that in response to food intake, as in response to stressors, plasma ACTH and corticosterone levels are increased. Moreover, it is shown for the first time that the release of $\mathrm{CRH}$ and $\mathrm{BN}$-like peptides in the amygdala, as assessed by in vivo microdialysis, was markedly increased by both stressor exposure and feeding. It is suggested that the central amygdala, and particularly CRH and/or BN neurons within this region, are fundamental in mediating the response to emotionally laden events, irrespective of whether they are negatively or positively charged.

\section{MATERIALS AND METHODS}

Subjects and surgical procedures. Male Sprague Dawley rats weighing $\sim 350-450$ gm $(n=50)$ were individually housed in standard clear plastic cages and were maintained on a $12 \mathrm{hr}$ light/dark cycle (6:30 A.M.-6:30 P.M. light phase). Animals had free access to Purina Lab Chow and water. All experimental procedures followed the guidelines of the $\mathrm{Ca}$ nadian Council on Animal Care and were approved by the Research Ethics Committee of the University of Ottawa. Rats were anesthetized $(60 \mathrm{mg} / \mathrm{kg}$ pentobarbital, i.p.) and stereotaxically implanted with a 20 gauge guide cannula containing a removable 24 gauge obturator aimed at the central nucleus of the amygdala. The placement coordinates (Paxinos and Watson, 1982) with level skull were anteroposterior, $-2.3 \mathrm{~mm}$; dorsaventral, $-7.0 \mathrm{~mm}$; and lateral, $\pm 4.2 \mathrm{~mm}$. The guide cannula protruding from a custom-manufactured Delrin pedestal was secured to the skull with four screws and dental cement. After surgical recovery (a minimum of $7 \mathrm{~d}$ ), animals were transferred to individual testing chambers and allowed to acclimate for $2 \mathrm{~d}$ before testing. The testing chambers comprised Plexiglas cages $(25 \times 35 \times 34 \mathrm{~cm})$ with a stainless steel grid floor. Food (powdered Purina Lab Chow) was available through a 3 $\mathrm{cm}$ hole centered in a short tunnel $(6.5 \times 6.5 \times 10 \mathrm{~cm})$ protruding from the cage. A food cup located beneath the hole was positioned atop an electronic scale, permitting continuous monitoring of food consumption.

Carotid cannulation for blood sampling. For some experiments, rats were implanted with carotid arterial catheters under aseptic conditions. The carotid artery was exposed by blunt dissection, and a small incision was made using a 23 gauge needle. The catheter, consisting of silicone tubing (Dow Corning) and polyethylene (PE-50) tubing, was inserted into the artery, ligated to the vessel, tunneled subcutaneously, and exteriorized at the neck level. During sampling, the cannula was connected to a remote syringe using a tethering jacket and a swivel assembly that permitted animals to move about freely in their cages during the experiment.

In vivo microdialysis. Two hours before testing, rats were briefly anesthetized with halothane, and the obturator within the guide cannula was replaced with a microdialysis probe. The concentric microdialysis probe had $2.5 \mathrm{~mm}$ of active membrane (250 $\mu \mathrm{m}$ outer diameter) of regenerated cellulose (6000 molecular weight cutoff; Spectrum Medical Industries) that protruded into the central nucleus of the amygdala. Each probe was secured with a retaining screw and connected via polyethylene tubing (Intermedic, Clay Adams, NJ) to a liquid swivel and a $2.5 \mathrm{ml}$ infusion syringe (Hamilton) attached to a pump (model 22, Harvard). Microdialysis probes were perfused at $2 \mu \mathrm{l} / \mathrm{min}$ with filtered Kreb'sRinger phosphate (KRB) solution consisting of (in $\mathrm{mM}$ ): $2.7 \mathrm{~K}^{+}, 145$ $\mathrm{Na}^{+}, 1.35 \mathrm{Ca}^{2+}, 1.0 \mathrm{Mg}^{2+}, 150 \mathrm{Cl}^{-}, 0.05$ ascorbate, $\mathrm{pH} 7.4$ (Moghaddam and Bunney, 1989), and BSA (0.1\%). On collection, each sample $(40-60 \mu \mathrm{l})$ was immediately frozen on dry ice and stored at $-80^{\circ} \mathrm{C}$ until radioimmunoassay (RIA) analyses. The efficiency of the microdialysis probes in terms of peptide recovery was assessed in vitro as follows. Probes were first submerged in a plain KRB solution and flushed with perfusion medium (KRB with $0.1 \%$ BSA) at $2 \mu \mathrm{l} / \mathrm{min}$ for $1 \mathrm{hr}$. They were then switched to tubes containing either [ ${ }^{125} \mathrm{I}$-Tyr0]CRF or $\left[{ }^{125} \mathrm{I}\right.$ Tyr4]BN in KRB solution. The average peptide recovery was $3.3 \pm 0.6 \%$ for $\mathrm{CRH}$ and $9.2 \pm 0.15 \%$ for BN over five successive sampling periods. When the solution bathing the probes was changed from one containing either of the ${ }^{125}$ I-labeled peptides to that of plain KRB, there was only a slight carryover effect on the first sample $(<0.6 \%)$, dropping to an average of $0.15 \%$. Reinsertion of the probes into the solution of iodinated peptide was accompanied by recovery of counts in the perfusate to the level originally seen with that probe within the first sampling period.

RIAs. The detection and quantification of $\mathrm{CRH}$ was achieved through a solid-phase high-sensitivity adaptation or modification (Maidment and Evans, 1991) of the double-antibody liquid phase RIA originally described by Vale and colleagues (1983). BN-like peptides were detected using a similar solid-phase RIA (Plamondon and Merali, 1997). Briefly, protein A/G (Calbiochem, La Jolla, CA)-coated Immulon-4 wells (Dynatech, Chantilly, VA) were incubated with anti-CRH serum (rC70, kindly provided by W. Vale, The Salk Institute, La Jolla, CA) or anti-BN serum ( $\alpha$-BN2, kindly provided by Dr. T. Moody, NCI, Rockville, MD) for $2 \mathrm{hr}$ at $20^{\circ} \mathrm{C}$. Samples, standards (reconstituted in the KRB solution, ranging from 0.05 to $250 \mathrm{fmol} /$ well), or blanks were incubated for $24 \mathrm{hr}$ at $4^{\circ} \mathrm{C}$. Next, $25 \mu \mathrm{l}$ of assay buffer containing $5000-6000 \mathrm{cpm}$ of $\left[{ }^{125} \mathrm{I}-\right.$ Tyr0]rCRF (Amersham, Oakville, Ontario, Canada) or [ [25I-Tyr4]BN (iodinated in-house, as per Salacinski et al., 1981) was added to each well and incubated for an additional $24 \mathrm{hr}$ period at $4^{\circ} \mathrm{C}$. Finally, the wells were rinsed and separated, and their residual radioactivity was counted in a gamma counter (Cobra II Auto-gamma). A four-parameter logistic curve fit model was used for interpolation of the standard curves. Sensitivity of the assay was typically $\sim 0.1$ and $2 \mathrm{fmol} /$ well for CRH and BN, respectively.

The specific anti-CRF serum used in the study recognized $\mathrm{CRH}_{1-41}$ and displayed negligible cross-reactivity with other related peptides (Vale et al., 1983), including urotensin 1 and urocortin (data not shown). The BN antibody used in the RIAs recognized the C-terminal fragment of $\mathrm{BN}$ and has been demonstrated to strongly cross-react with amphibian BN $(100 \%)$ and certain mammalian BN-like peptides, including gastrinreleasing peptide $(\mathrm{GRP})_{1-27}(110 \%)$ and $\mathrm{GRP}_{18-27}$ [neuromedin C $(82 \%)]$ but only weakly with $\mathrm{GRP}_{1-16}$, neuromedin B (NMB)-10, NMB32 , or substance $\mathrm{P}(\leq 0.1 \%)$ (Moody et al., 1981). We have shown in the past that the major source of BN-like immunoreactivity from the hypothalamus is attributable to GRP (Merali and Kateb, 1993).

To verify the identity of the $\mathrm{CRH}$-immunoreactive (ir-CRH) material detected in the dialysates, probes positioned within the central nucleus of the amygdala $(n=3)$ were perfused at $2 \mu \mathrm{l} / \mathrm{min}$ for $8 \mathrm{hr}$. The total dialysate volume $(960 \mu \mathrm{l})$ collected over ice was split in two aliquots (480 $\mu \mathrm{l}$ each) and freeze-dried for two distinct HPLC analyses. The freezedried samples were reconstituted and separated by a reverse-phase HPLC system consisting of a Spectra-Physics (San Jose, CA) P-2000 gradient pump and a C18 Vydac $218 \mathrm{TP} 54$ column $(250 \times 4.6 \mathrm{~mm}, 5 \mu$, $\mathrm{C} 18,300 \AA$ pore size). The column was equilibrated with mobile phase $\mathrm{A}$ [ $10 \%$ acetonitrile (AcN) with $0.1 \%$ trifluoroacetic acid (TFA) in $\mathrm{H}_{2} \mathrm{O}$ ], and peptides were eluted with mobile phase $\mathrm{B}(90 \% \mathrm{AcN}$ with $0.1 \%$ TFA in $\mathrm{H}_{2} \mathrm{O}$ ) using a linear gradient (from $\mathrm{A}=100 \%$ to $\mathrm{B}=100 \%$, over 50 $\mathrm{min}$ ), at a flow rate of $1 \mathrm{ml} / \mathrm{min}$. Authentic CRH standard (rat/human $\mathrm{CRH}_{1-41}$, Peninsula Laboratories) was run under identical conditions, and the absorbance of the elutant was monitored at $214 \mathrm{~nm}$ (absorbance detector 783A; Applied Biosystems, Foster City, CA). The peak elution time for synthetic CRH was $31.8 \mathrm{~min}$, and that of ir-CRH material contained within the dialysate eluted in fractions collected over 31-32 min, coinciding with the elution time of authentic CRH (Fig. 1, top). The major peak of BN-like immunoreactive (ir-BN) material eluted in fractions collected over 17-18 min and coincided with the elution time of synthetic $\mathrm{GRP}_{1-27}$ (Peninsula Laboratories) of $17.4 \mathrm{~min}$, whereas the smaller peak (preceding or shouldering the major peak) that eluted with fractions collected over 14-16 min corresponded with elution time of synthetic $\mathrm{GRP}_{18-27}$ (Fig. 1, bottom).

The identity of eluting peptides was replicated and verified using (1) the same HPLC conditions but a different microdialysis sample and (2) a second distinct set of HPLC conditions. This alternate HPLC procedure used a different C18 column (Jupiter; $250 \times 4.6 \mathrm{~mm}, 5 \mu, \mathrm{C} 18,300 \AA$ คore size; Phenomenex, Torrance, CA) and the following elution conditions. The system was equilibrated with mobile phase A (10\% AcN with $0.1 \%$ 

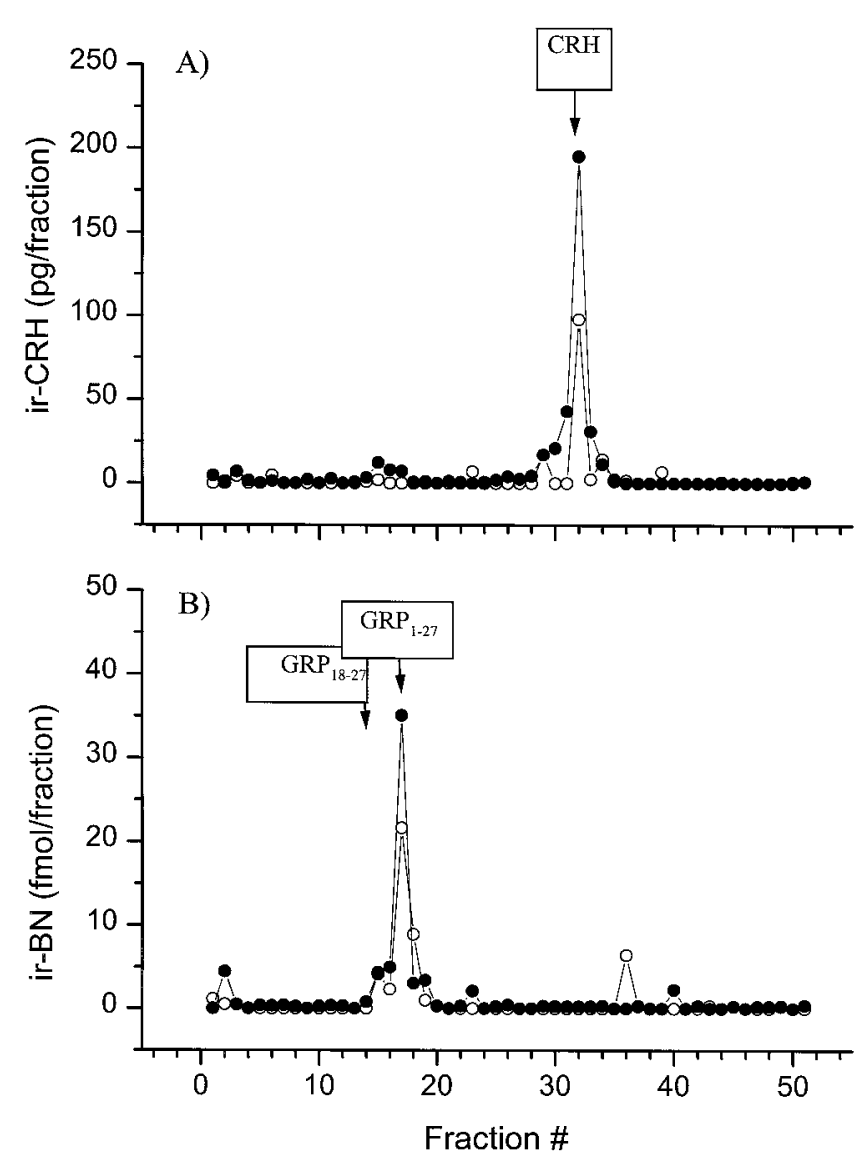

Figure 1. HPLC separation and identification of endogenous CRH and BN-like immunoreactivity in microdialysis samples. A, HPLC profile ir-CRH material from dialysates collected from two separate animals (open and filled circles, respectively). The boxed arrow indicates the elution time for synthetic CRH using UV detection. $B$, HPLC profile of endogenous ir-BN-like material eluting from the pooled dialysate compared with the elution time for synthetic $\mathrm{GRP}_{1-27}$ and $\mathrm{GRP}_{18-27}$ (boxed arrows).

TFA in $\left.\mathrm{H}_{2} \mathrm{O}\right)$, and peptides were eluted with mobile phase $\mathrm{B}(90 \% \mathrm{AcN}$ with $0.1 \%$ TFA in $\mathrm{H}_{2} \mathrm{O}$ ) using a linear gradient (from $\mathrm{A}=100 \%$ to $\mathrm{B}=$ $100 \%$ in $100 \mathrm{~min}$ ) at a flow rate of $1 \mathrm{ml} / \mathrm{min}$. The eluting fractions were collected every $30 \mathrm{sec}$ and freeze-dried for subsequent RIA analyses. Under this set of conditions, synthetic CRH eluted at $50.3 \mathrm{~min}$, and the major peak of endogenous ir-CRH material from the dialysate was contained within fractions collected over 50-51 min. BN immunoreactivity from the sample eluted at $26.5 \mathrm{~min}$ (minor peak) and $29 \mathrm{~min}$ (major peak), once again corresponding to retention times of synthetic $\mathrm{GRP}_{18-27}(25.9 \mathrm{~min})$ and $\mathrm{GRP}_{1-27}(29.2 \mathrm{~min})$, respectively (data not shown). These results are consistent with the assertion that the ir-CRH material in the amygdaloid dialysate represents authentic $\mathrm{CRH}$, whereas ir-BN-like material represents $\mathrm{GRP}_{1-27}$ and/or GRP ${ }_{18-27}$.

Plasma ACTH and corticosterone measurements. Corticosterone and ACTH levels were measured using commercial RIA kits (ICN Pharmaceuticals, Costa Mesa, CA).

Experimental design and procedures. Thirty rats with probes aimed at the central nucleus of the amygdala participated in the initial experiment (stress study). The probes were continually perfused with KRB, and dialysates were pooled every $30 \mathrm{~min}$, throughout the experiment. After collection of five baseline samples, rats in the "stress" group $(n=20)$ were manually restrained for $20 \mathrm{~min}$. The restraint procedure consisted of a rat, situated on the floor of the test chamber, being lightly grasped about the shoulder and forelimbs by an experimenter's gloved hand. Thus, the ability of the animals to move was prevented. Dialysate samples continued to be collected (every $30 \mathrm{~min}$ ) for $2.5 \mathrm{hr}$, after which the animals were again restrained (for $20 \mathrm{~min}$ ), and dialysates were collected for an additional $2.5 \mathrm{hr}$. The control or "no stress" group $(n=10)$ underwent an identical collection procedure; however, they were not stressed and remained undisturbed in the test cages throughout the experiment. In addition to the dialysate samples, blood $(100 \mu l)$ was collected from a tail nick immediately before restraint, just before release from restraint, and again just before the end of the second restraint period. Plasma samples were stored at $-80^{\circ} \mathrm{C}$ for subsequent $\mathrm{ACTH}$ and corticosterone analyses.

A second experiment (feeding study) using 10 rats assessed central amygdaloid CRH and BN-like peptide fluctuations associated with various spontaneous ingestive states in animals with ad libitum access to food (powdered Purina Lab Chow). Probes were inserted into the guide cannula at 2:00 P.M. (4 hr before dark onset) and were continually perfused with KRB solution. Commencing $2 \mathrm{hr}$ after probe insertion, dialysates were pooled every $30 \mathrm{~min}$ (over $5 \mathrm{hr}$ ). The food cup was positioned atop an electronic scale, thus permitting continuous monitoring of food consumption. When an animal initiated a meal, the $30 \mathrm{~min}$ dialysate sampling period began anew. A meal was defined as consumption of a minimum of $0.3 \mathrm{gm}$ during the $30 \mathrm{~min}$ sampling period. The meals ranged in size from 0.3 to $3.1 \mathrm{gm}$ (mean \pm SEM, $1.26 \pm 0.12 \mathrm{gm}$ ), and the first meal usually occurred within 90 min of dark onset. The 30 min period before meal initiation was considered the preprandial period, and the $30 \mathrm{~min}$ interval preceding this was considered the baseline. The postprandial period was the $30 \mathrm{~min}$ period after meal termination, during which no food was consumed. If during this time a new meal was initiated, then the postprandial was considered as the subsequent $30 \mathrm{~min}$ period.

Whereas the preceding experiment assessed peptide and endocrine variations in the context of spontaneous meals, a separate experiment evaluated plasma ACTH and corticosterone levels before and after presentation of a palatable snack (graham wafers). This experiment was conducted during the light phase of the diurnal cycle (10 A.M.-12 P.M.) among animals that had previously experienced this particular type of snack (on four occasions, to reduce any neophobic responses). Rats ( $n=$ 8 ) equipped with a carotid artery catheter had blood samples drawn at 20 , 10 , and $0 \mathrm{~min}$ before food presentation. Rats were then presented with the familiar palatable food (16 gm of graham wafers) for a $10 \mathrm{~min}$ period, during which all animals readily consumed some food (mean \pm SEM, $3.40 \pm 0.84 \mathrm{gm})$. Blood samples were drawn 5 min after meal initiation (i.e., during the $10 \mathrm{~min}$ meal), and then again at 15,30, and $60 \mathrm{~min}$ after meal presentation or initiation. Plasma samples were stored at $-80^{\circ} \mathrm{C}$ for subsequent ACTH and corticosterone determinations.

Histology. At the end of each experiment, animals were perfused under heavy sodium pentobarbital anesthesia, and the brains were extracted, sectioned, and stained for histological examination.

Statistical analyses. In all microdialysis experiments, only data from correctly positioned probes (verified histologically) were included for statistical analyses (i.e., excluding values from animals with misaligned or "off-site" probes). From animals included in the statistical analyses, there were occasional missing values attributable to accidental sample loss, assay error, or flow problems, contributing to variations in sample size. As in the case of most microdialysis studies assessing other central neurotransmitters (such as dopamine), appreciable interindividual and interexperiment variability was noted in the present experiments with respect to baseline interstitial CRH levels. This variability may have stemmed from genuine differences between animals as well as technical aspects related to the microdialysis procedure, including variability in the relative peptide recovery of individual microdialysis probes, subtle differences in probe placements, and the variability associated with individual RIAs. Accordingly, in the present investigation, the baseline values of each subject were averaged and defined as $100 \%$. All values were then expressed as a percentage of the average baseline values. Repeated ANOVA measures with sample blocks (baseline, poststress 1, and poststress 2) and samples nested within each block treated as within measures were performed independently for both CRH and BN. Post hoc comparisons were conducted using Tukey's tests. In the feeding study (experiment 2) all values were expressed as a percentage of baseline. For some animals, multiple values were available for particular feeding state(s), and these values were averaged before repeated measures ANOVA. The baseline, preprandial, prandial, and postprandial periods were treated as a within factor.

Plasma concentrations of ACTH and corticosterone values were derived from all animals (irrespective of probe position) before and after the two stressor presentations and were analyzed by repeated measures ANOVA. In the food intake study, values from all animals with patent blood sampling cannula were subjected to repeated measures ANOVA to compare both the ACTH and corticosterone concentrations at various 


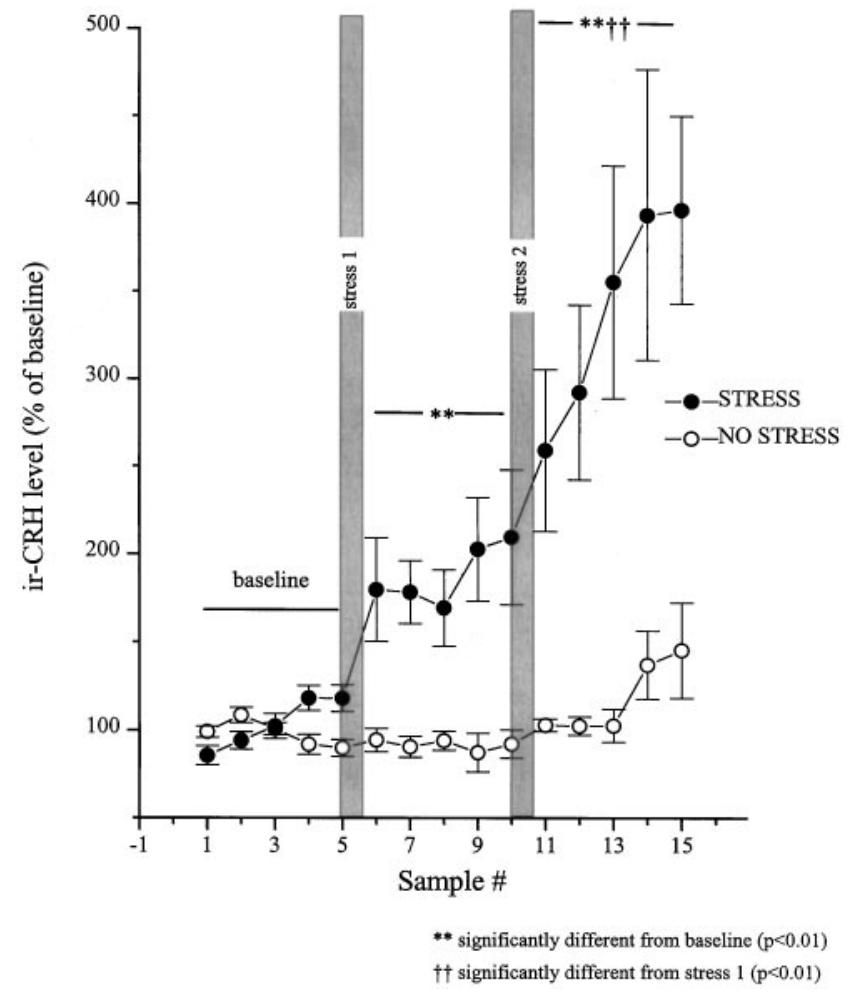

Figure 2. Restraint stress-induced release of CRH at the central nucleus of the amygdala as measured by in vivo microdialysis. Dialysate samples were collected uninterrupted throughout the experiment, and samples were pooled every $30 \mathrm{~min}$. After collection of five baseline samples, rats in the stress group $(n=8-10)$ were hand-restrained ( filled circles) for 30 min episodes on two separate occasions (shaded vertical bars, stress 1 and stress 2). The rats in the no-stress (control) group $(n=5-7)$ were left undisturbed throughout (open circles). The five baseline values from each of the subjects were averaged and defined as $100 \%$. All values were then expressed as a percent of that baseline. Basal CRH values for the no stress and stress groups were $2.77 \pm 0.11$ and $2.31 \pm 0.39 \mathrm{fmol} / \mathrm{sample}$, respectively.

times before food presentation $(20,10$, or $0 \mathrm{~min})$ and at the various times during or after food presentation $(5,15,30$, or $60 \mathrm{~min})$.

\section{RESULTS}

\section{Restraint stress-induced release of $\mathrm{CRH}$ and $\mathrm{BN}$-like peptides at the amygdala}

Data from animals with correctly positioned probes $(n=10)$ revealed that the interstitial $\mathrm{CRH}$ varied as a function of the stress condition (restraint or no stress) $\times$ blocks (baseline, stress 1 , and stress 2$) \times$ samples (time) interaction $\left(F_{(8,144)}=4.72 ; p<\right.$ 0.01). Levels of BN-like peptides varied as a function of stress condition $\times$ samples interaction $\left(F_{(4,56)}=9.37 ; p<0.01\right)$. The comparisons of the means of the simple effects constituting these interactions revealed that among nonstressed rats both $\mathrm{CRH}$ and BN levels were stable throughout the session. The initial stressor application resulted in an immediate (within the initial $30 \mathrm{~min}$ ) and sustained (over $2.5 \mathrm{hr}$ ) rise in the interstitial levels of $\mathrm{CRH}$ (Fig. 2). After the second stressor application, a further increase in the release of $\mathrm{CRH}$ was evident, which continued to rise for the duration of the test period.

In a parallel control no-stress group of animals with probes correctly positioned at central nucleus $(n=7), \mathrm{CRH}$ release did not fluctuate significantly over time. The stress effect appeared to be specific to the central nucleus, because there was no significant change in $\mathrm{CRH}$ release from off-site probes with detectable levels of the peptide ( $n=5$ of 10 off-site probes; data not shown). See Figure 3 for location of the microdialysis probes.

The stressor also promoted an immediate rise in the release of $\mathrm{BN}$-like peptides; compared with $\mathrm{CRH}$ release, this response was slower in onset and less pronounced but continued to increase progressively over the entire session (Fig. 4). After stressor reexposure, a further increase was noted that persisted to the end of the test period $(2.5 \mathrm{hr})$. As in the case of $\mathrm{CRH}$, this response was stressor-related, as nonrestrained animals did not show significant variations in the interstitial levels of BN-like peptides. Yet, in nonstressed animals a modest nonsignificant increase on BN-like peptides was evident near the end of the session, a few hours before dark onset, raising the possibility that circadian factors may also have contributed to BN rise in stressed animals. It is of interest to note that the fluctuations of BN-like peptides were not as site-specific as those of $\mathrm{CRH}$, because some off-site probes with detectable ir-BN levels $(n=6)$ showed some elevation in the release of ir-BN, but not until much later $(1.5 \mathrm{hr}$ after second stressor application) (data not shown). See Figure 3 for location of the microdialysis probes.

\section{Effect of acute restraint episodes on circulating ACTH and corticosterone levels}

As expected, the plasma ACTH and corticosterone concentrations were significantly elevated by the stressor treatment $\left(F_{(9,23)}\right.$ $=29.88$ and $F_{(9,22)}=100.85$, respectively; $\left.p<0.01\right)$. The multiple comparisons indicated that relative to basal ACTH concentrations $(50.1 \pm 9.6 \mathrm{pg} / \mathrm{ml})$, elevations of the hormone were seen immediately after the first (395.4 $\pm 63.9 \mathrm{pg} / \mathrm{ml})$ and second $(274.3 \pm 96.9 \mathrm{pg} / \mathrm{ml})$ stressor exposures. Likewise, compared with baseline $(9.5 \pm 2.3 \mu \mathrm{g} / 100 \mathrm{ml})$, plasma corticosterone levels were increased both after the first and the second stressor exposures $(25.8 \pm 2.6$ and $23.5 \pm 1.8 \mu \mathrm{g} / 100 \mathrm{ml}$, respectively). It is noteworthy that the levels of ACTH and corticosterone observed after the first and second restraint periods were comparable to one another, whereas the interstitial levels of $\mathrm{CRH}$ and $\mathrm{BN}$ were significantly higher after the second stress episode compared with the first. Because a baseline blood sample was not taken immediately before the second stress period, the relative magnitude of the hormonal changes cannot be determined.

\section{Meal-elicited release of $\mathrm{CRH}$ and $\mathrm{BN}$-like peptides at the amygdala}

Figure 5 shows the interstitial CRH (top) and ir-BN (bottom) levels as a percent of baseline before, during, and after ingestion of a spontaneous meal. Both peptides varied significantly over the test session $\left(\mathrm{CRH}, F_{(6,18)}=21.62 ; p<0.0001 ; \mathrm{BN}, F_{(6,18)}=9.11\right.$; $p<0.007)$. The multiple comparisons revealed that during the preprandial period, neither peptide varied from baseline. However, during ingestion and during the postprandial period, interstitial levels of both $\mathrm{CRH}$ and $\mathrm{BN}$ were markedly increased. Indeed, the meal-elicited rise of $\mathrm{CRH}$ was as great as that associated with the first restraint period (compare Figs. 2, 4).

The positions of probes on target, as well as those misaligned (and thus excluded from analyses), are depicted in Figure 6. This response appeared to be specific to the central nucleus of the amygdala, because the off-site probes failed to show meal-related fluctuations in release of $\mathrm{CRH}$ and/or BN-like peptides (data not shown).

Plasma ACTH and corticosterone from samples taken before and after palatable food consumption (mean \pm SEM, $3.7 \pm 0.7$ 


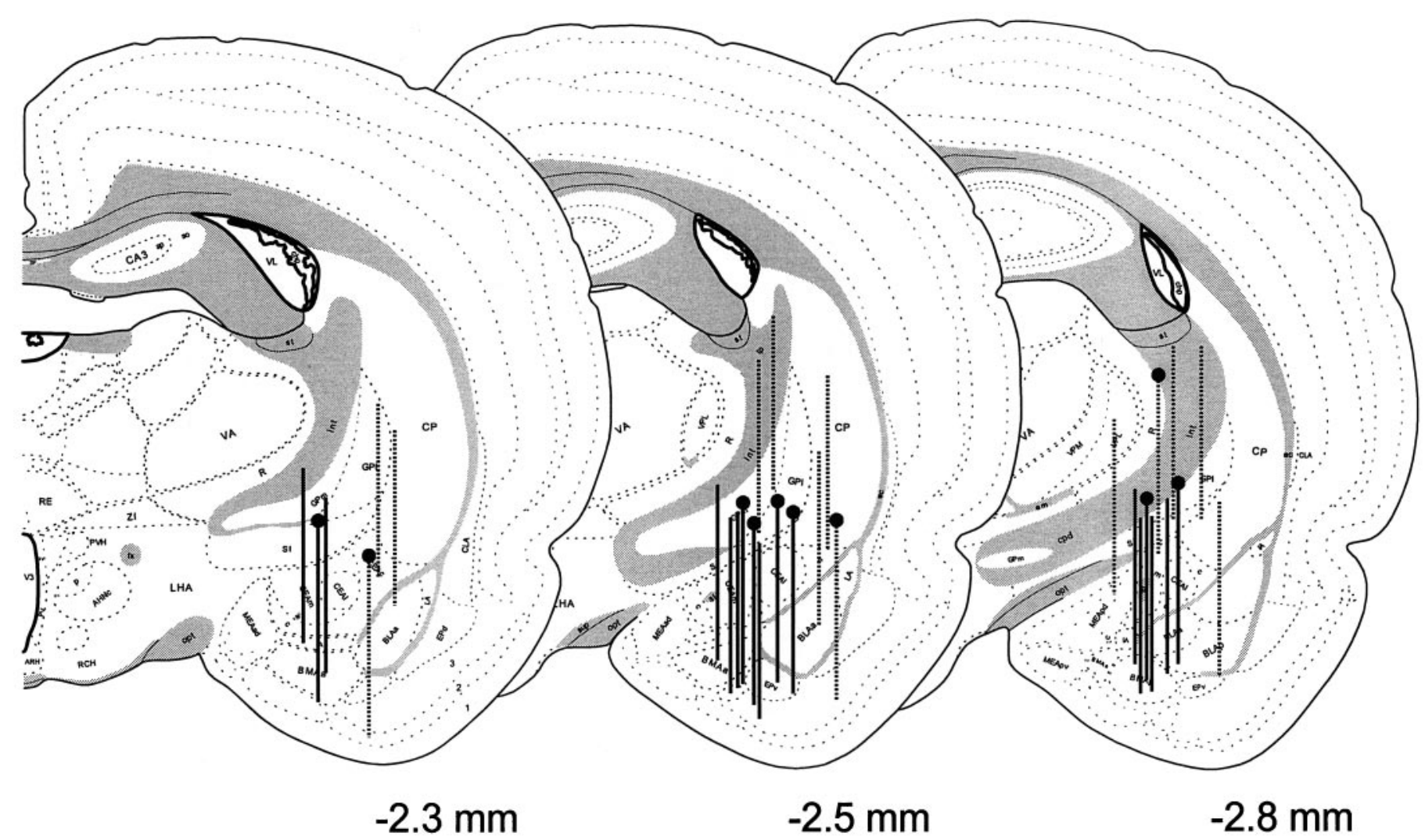

Figure 3. Anatomical localization of the microdialysis membranes aimed at the central nucleus of the amygdala in the stress study. A series of consecutive brain sections bearing the trace of microdialysis probes were stained, the most ventral location of the probe tip was determined, and a 2.5 $\mathrm{mm}$ line was drawn vertically, tracing the estimated location of the active region of the probe. Solid vertical lines with pinheads represent probes of animals included in the no-stress control group. The off-site probes (broken vertical line with pinhead) were excluded from analysis. The probe placements of animals included in the stress group are identified with solid vertical lines, whereas those considered off-site and excluded from analysis are depicted by broken vertical lines.

gm) were both found to vary over the course of the session $\left(F_{(6,36)}\right.$ $=3.91 ; p<0.01 ; F_{(6,30)}=6.74 ; p<0.01$, respectively). The multiple comparisons confirmed that ACTH levels were significantly increased during ingestion and $15 \mathrm{~min}$ after initiation of consumption and declined thereafter (Fig. 7). The rise of corticosterone was slower than that of ACTH and was significant at 15 and $30 \mathrm{~min}$ after meal initiation and then declined at $60 \mathrm{~min}$. It is noteworthy that whereas the extent of the $\mathrm{CRH}$ and $\mathrm{BN}$ increase induced by food ingestion was comparable to that noted during a similar period after restraint exposure, the meal-elicited rise of ACTH was of a smaller magnitude than that elicited by the stressor, although both treatments provoked comparable elevations of corticosterone.

\section{DISCUSSION}

Most studies that have assessed the effects of stressors on central $\mathrm{CRH}$ have done so using relatively indirect techniques, such as measurement of mRNA expression, immunohistochemistry, or postmortem tissue level analyses (Tilders et al., 1993; Kovács and Sawchenko, 1996; Schmidt et al., 1996). The former two approaches are indicative of potential variations of $\mathrm{CRH}$ but do not necessarily reflect actual peptide release. Moreover, these techniques, like postmortem analyses of CRH content, do not permit evaluation of dynamic within subject variations that may occur over the course of a treatment regimen. In the present investigation, we demonstrate the feasibility of in vivo microdialysis combined with highly sensitive solid-phase RIAs in the measurement of interstitial levels of CRH and BN-like peptides. Furthermore, using HPLC fractionation of brain dialysates and external standards in combination with RIA and UV detection, respectively, we demonstrate that the $\mathrm{CRH}$ immunoreactivity within the dialysates corresponds to authentic CRH. In addition, through similar fractionation and analyses we identified the ir-BN material in the dialysate to represent $\mathrm{GRP}_{1-27}$ and/or $\mathrm{GRP}_{18-27}$, the mammalian counterparts of amphibian BN (Wada et al., 1990). In both instances, this was further confirmed through the use of two different columns and gradient conditions, wherein the variations of the retention times for the respective peptide standards was associated with a corresponding shift in immunoreactive peaks eluting from the dialysate samples.

Stressor exposure in the present investigation produced a pronounced and sustained increase in the release of $\mathrm{CRH}$ at the central nucleus of amygdala. This increase was evident soon after stressor onset and was still pronounced and stable $2.5 \mathrm{hr}$ afterward. Earlier studies had demonstrated that in vivo $\mathrm{CRH}$ release was elevated by stressors such as restraint or drug (alcohol or cannabinoid) withdrawal (Pich et al., 1995; Rodríguez de Fonseca et al., 1997). In these experiments, the detection and quantification of CRH involved incorporation of anti-CRF serum directly into the medium perfusing the microdialysis probes. In the present investigation, CRH changes were observed using a simpler, more direct method that did not require spiking the perfusion medium with the anti-CRF serum and yielded comparable 


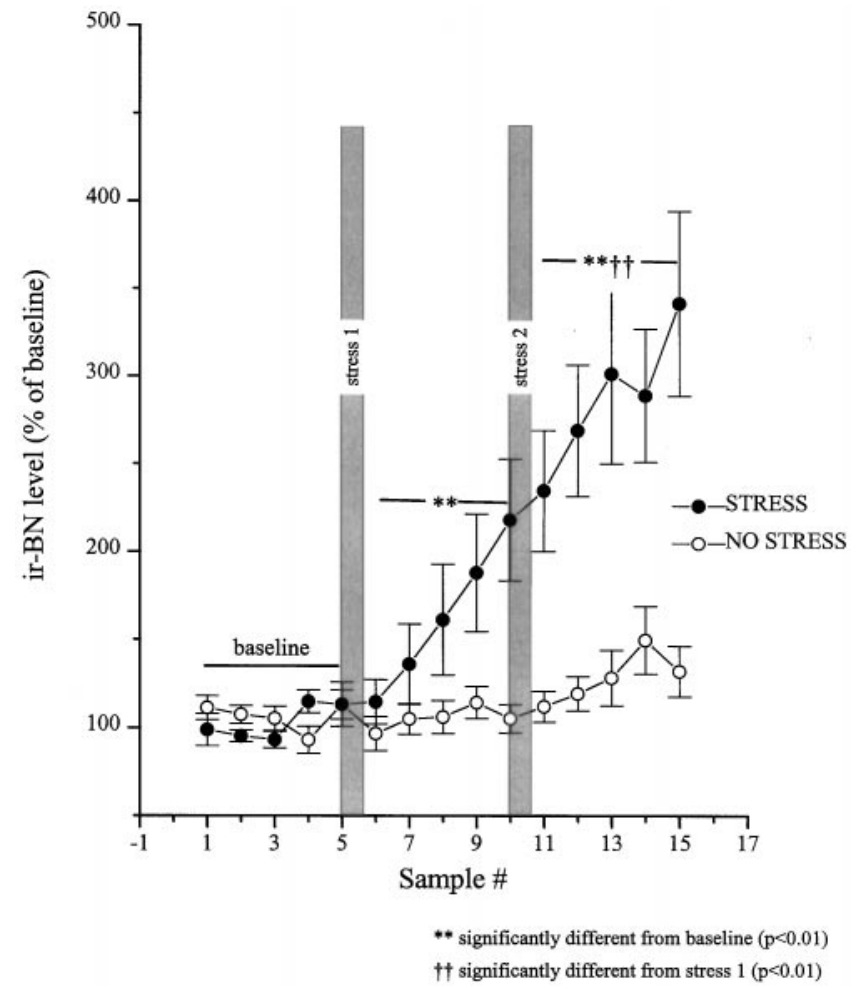

Figure 4. Restraint stress-induced release of BN-like peptides from the central nucleus of the amygdala as measured by in vivo microdialysis. Dialysate samples were collected uninterrupted throughout the experiment, and samples were pooled every $30 \mathrm{~min}$. After collection of five baseline samples, rats in the stress group $(n=10)$ were hand-restrained ( filled circles) for 20 min episodes on two separate occasions (shaded bars, stress 1 and stress 2). The rats in the no stress control group $(n=7)$ were left undisturbed (open circles). The five baseline values from each of the subjects were averaged and defined as $100 \%$. All values were then expressed as a percent of that baseline. Basal values for $\mathrm{BN}$ immunoreactive peptides were $3.01 \pm 0.42$ and $3.28 \pm 0.33 \mathrm{fmol} / \mathrm{sample}$ for the stress and no-stress groups, respectively.

basal interstitial levels of CRH. In both the study by Pich et al. (1995) and the present study, marked CRH elevations were evident in response to $20 \mathrm{~min}$ of restraint stress. Although the magnitude of the effects reported by Pich et al. (1995) was more pronounced, the effects also were more transient (40 min vs $2.5 \mathrm{hr}$ in the present study). These differences may have been related to several factors. In the study by Pich et al. (1995), inclusion of the $\mathrm{CRH}$ antibody into the dialyzing medium may have created a greater positive gradient for CRH from the interstitial fluid, resulting in a sharpened temporally limited CRH peak. Alternatively, the dynamics of CRH may have been influenced by the cues associated with the stressor. Specifically, in the report by Pich et al. (1995), the restraint was applied in a novel cage (thus the "stressful environment" comprised both the novel situation and restraint) after which the rat was returned to its home cage ("safe environment"). In contrast, in the present study the entire procedure was conducted in the rat's home cage. Thus it is possible that the otherwise neutral home cage cues may have taken on secondary aversive (or stressful) qualities, hence leading to more protracted peptide variations. This supposition is consistent with the view proposed by Lee and Davis (1997), who suggested that the amygdala plays a fundamental role in the fear response (being elicited by an identifiable stimulus and subsiding with the offset of this stimulus), whereas the bed nucleus of the
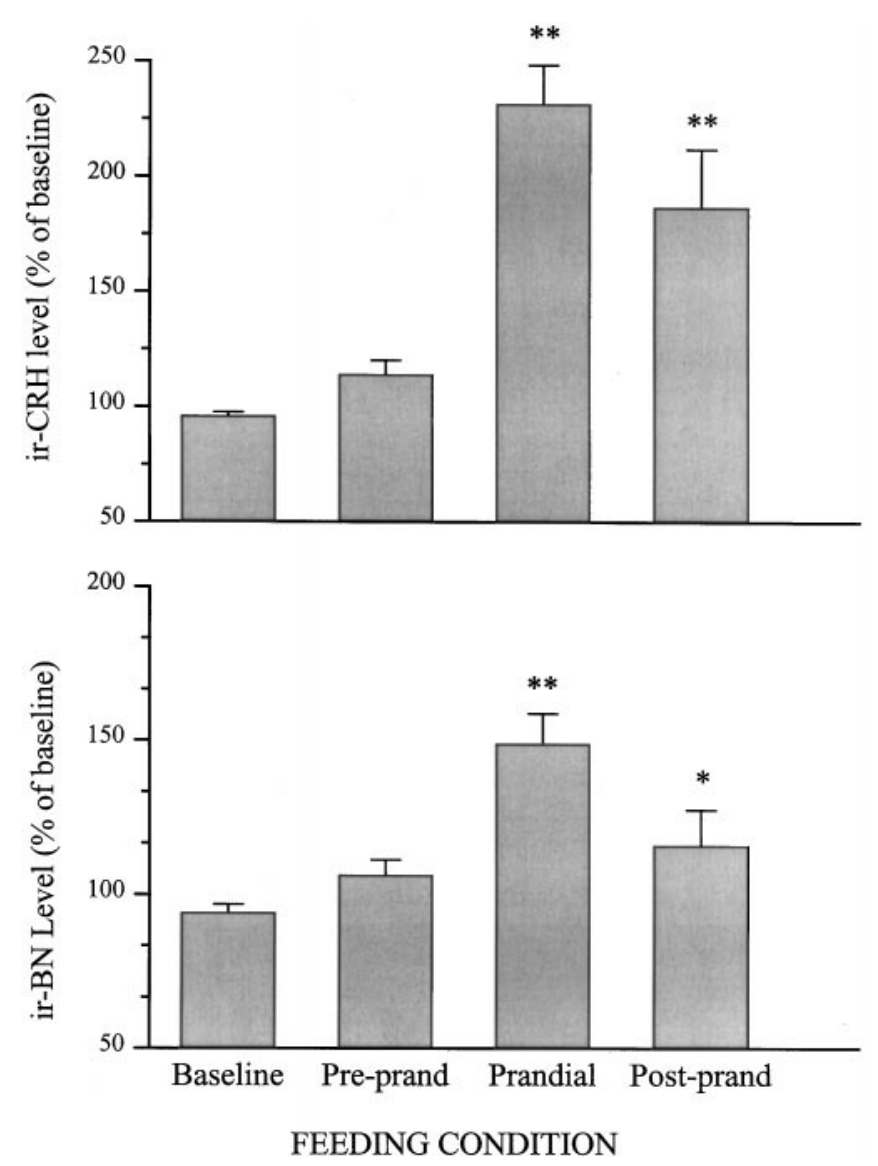

Figure 5. Meal-elicited release of $\mathrm{CRH}$ and BN-like peptides at the central nucleus of the amygdala. Microdialysate samples were collected continually and pooled every $30 \mathrm{~min}$ for $5 \mathrm{hr}$. The quantity of food ingested during each $30 \mathrm{~min}$ bin was noted. The $30 \mathrm{~min}$ period before meal initiation was considered the preprandial period, and the $30 \mathrm{~min}$ sample preceding this was considered the baseline. The postprandial period was the $30 \mathrm{~min}$ period after meal termination. The baseline value was defined as $100 \%$, and all other values were expressed as a percentage of this value. The meal-related CRH changes are presented at the top, whereas the changes in $\mathrm{BN}$-like peptides are shown at the bottom. The basal values for $\mathrm{CRH}$ and $\mathrm{BN}-$ like peptides were $0.95 \pm 0.12$ and $0.77 \pm$ $0.07 \mathrm{fmol} / \mathrm{sample}$, respectively.

stria terminalis, a primary target of the amygdaloid projections, is more closely aligned with more generalized anxiety states. In effect, applying the stressor in the animal's home cage resulted in the sustained CRH release even when the primary stressor was terminated.

Paralleling the $\mathrm{CRH}$ changes, release of $\mathrm{BN}$-like peptides was also induced by the stressor, a finding commensurate with our earlier postmortem results (Kent et al., 1998). The changes in BN-like peptide(s) developed relatively slowly over the poststress period. Because interstitial ir-BN levels increased progressively throughout the $2.5 \mathrm{hr}$ after the initial stressor, it is unclear whether the further rise after the second stressor actually reflects the consequences of the second restraint episode or a sustained effect of the initial restraint period. Nonetheless, the fact that increased release of BN-like peptides continued over time after termination of restraint, whereas the elevations of $\mathrm{CRH}$ release were relatively stable, raises the possibility that BN-like peptides may be important in subserving sustained emotional changes associated with a stressor experience. Of course, as in the case of $\mathrm{CRH}$ changes, the possibility cannot be dismissed that environ- 


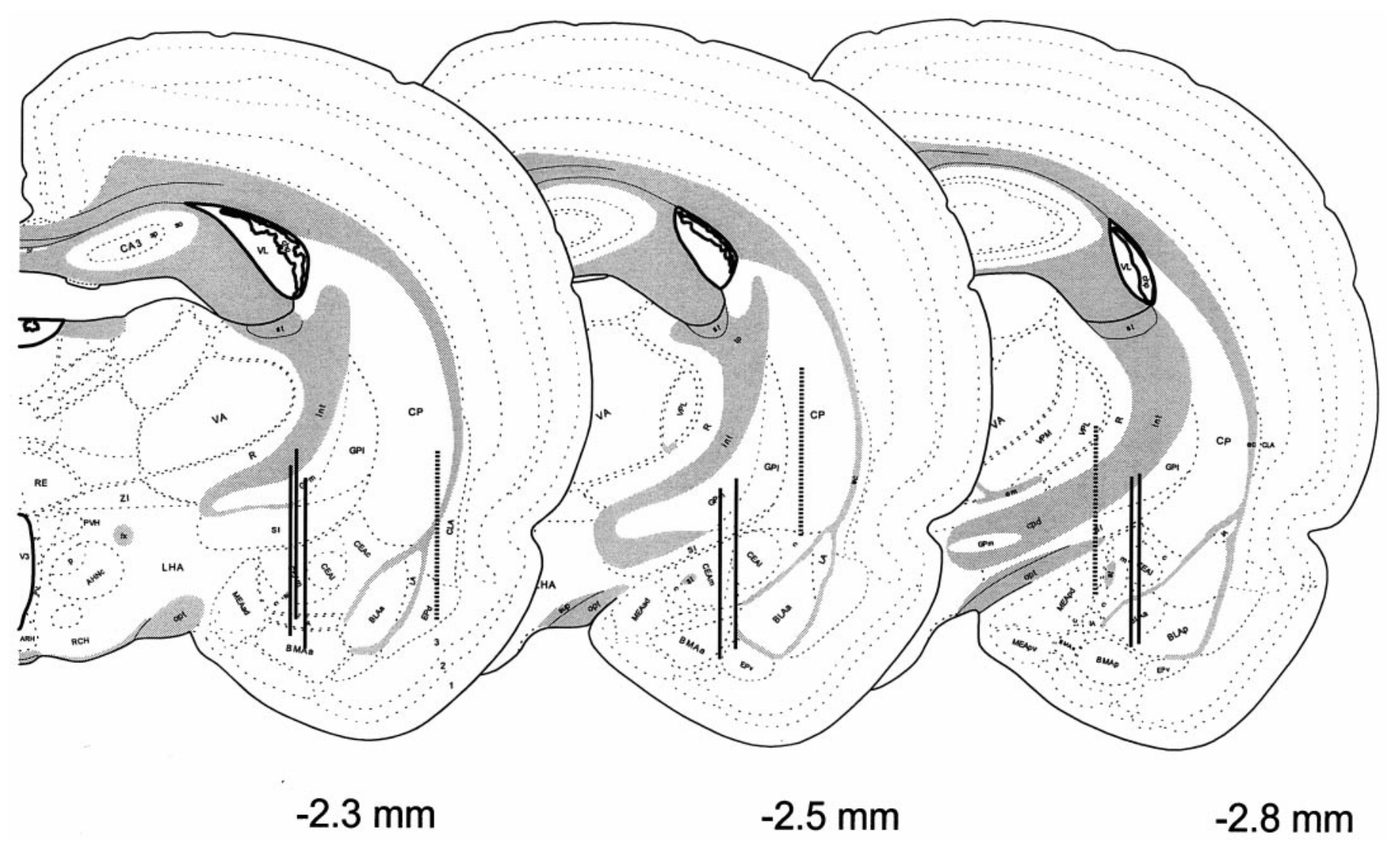

Figure 6. Anatomical localization of the microdialysis membranes aimed at the central nucleus of the amygdala in animals involved in the feeding study. Probe placements were identified and represented as described in Figure 3. Probe placements of animals included in the analysis $(n=7)$ are identified with solid vertical lines, whereas those of animals excluded from analysis attributable to misalignment (off-site, $n=3$ ) are depicted by broken vertical lines.

mental cues associated with the stressor and the peptide alterations are related to one another. In fact, because BN promotes ACTH release and this effect is prevented by pretreatment with CRH antagonists (Merali et al., 1994), the possibility ought to be considered that BN-like peptides provoke ACTH elevations by stimulating $\mathrm{CRH}$ release. The potential physiological role of $\mathrm{BN}$-like peptides at the central nucleus of the amygdala, particularly with respect to $\mathrm{CRH}$ release, remains to be elucidated. It is noteworthy that although the variations of $\mathrm{ACTH}$, corticosterone, and BN-like peptides were evident within $30 \mathrm{~min}$ of stressor initiation, the increase in BN-like immunoreactivity was not evident until $\sim 1 \mathrm{hr}$ after stressor onset. Accordingly, it is not likely that the plasma ACTH and/or corticosterone changes were causally related to variations of $\mathrm{BN}$-like peptides within the amygdala.

It has been suggested that the activation of HPA neurons may be a fundamental response to stressors. In this context, limbic regions, particularly the amygdala, may be essential in determining the response to processive stressors (requiring interpretation by higher brain structures), whereas systemic stressors (involving immediate physiological threat) may affect HPA activity through nonamygdaloid mechanisms (Herman and Cullinan, 1997). Indeed it has been suggested that the amygdala may be important in the formation, consolidation, and expression of those events that have been associated with aversive stimuli (Davis et al., 1994) and may activate the HPA via amygdaloid inputs to the hypothalamus (Gray et al., 1989; Menzaghi et al., 1993). Although not discounting these views, the present results make it clear that appetitive stimuli influence not only HPA activity but also the release of
$\mathrm{CRH}$ and $\mathrm{BN}$-like peptides at the central nucleus of the amygdala. Although restraint was clearly more effective in provoking the ACTH changes, the two treatments were approximately comparable in elevating circulating corticosterone levels. Similar prandial and/or postprandial ACTH and/or cortisol elevations have also been reported in human studies (Follenius et al., 1982; Al-Damluji et al., 1987; Karbonits et al., 1996). Moreover, indirect analyses of $\mathrm{CRH}$, vasopressin, and oxytocin indicated that among deprived animals, the presentation of water may provoke increased release of these peptides from the median eminence (Romero et al., 1995). Interestingly, in these animals the frustration of being presented with empty water bottles also had similar effects. Thus, these peptidergic changes may reflect general arousal rather than the response to aversive stimuli.

Although the central nucleus of the amygdala has long been considered to contribute to emotional responses, the view has also been expressed that this brain region plays an essential role in complex processes such as attention, secondary reinforcement, reward, and social behavior (Davis et al., 1994). In fact, in the present investigation in vivo, $\mathrm{CRH}$ and ir-BN changes were as pronounced after an appetitive stimulus as those elicited by the aversive event. Clearly, the amygdala is not uniquely responsive to aversive stimuli, and $\mathrm{CRH}$ and $\mathrm{BN}$-like peptides are released in response to appetitive events as well. This observation is reminiscent of the catecholaminergic responses noted at the prefrontal cortex and/or nucleus accumbens. Although once believed to be stress-specific, the catecholaminergic systems were subsequently found to be activated by stimuli with positive valence as well, 

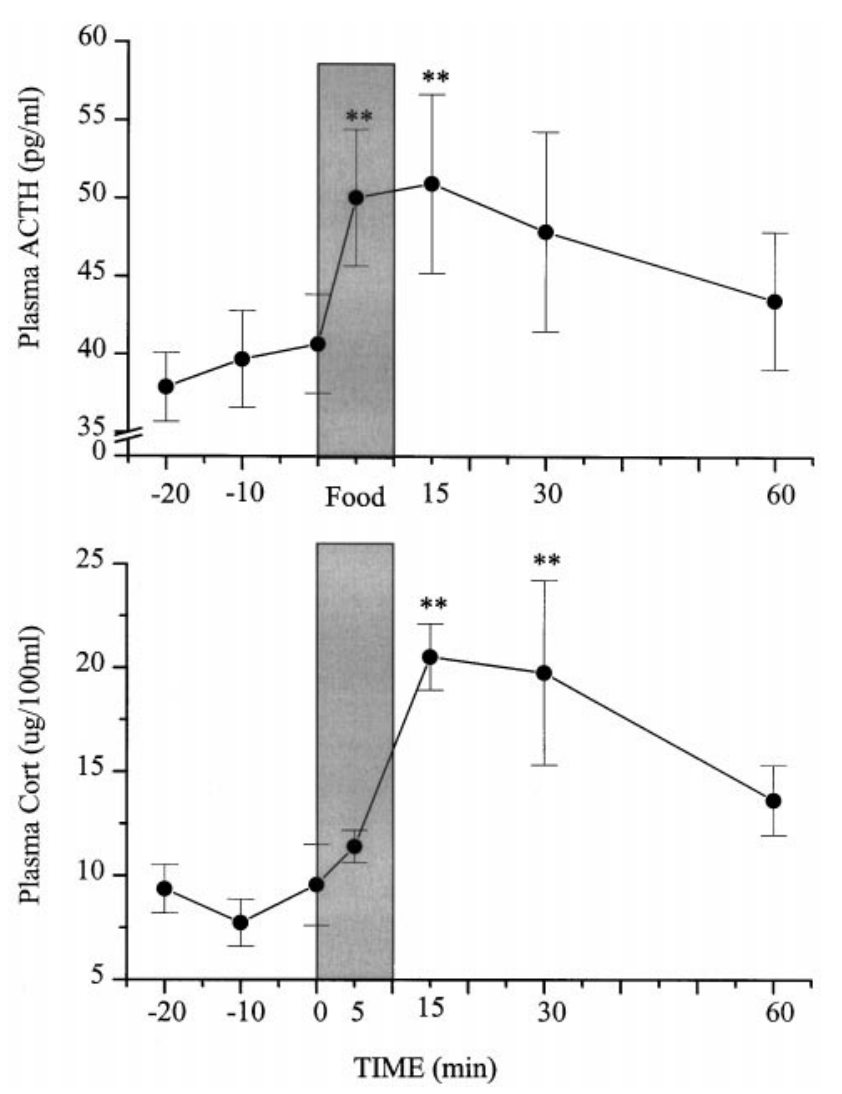

Figure 7. Effects of food ingestion on circulating ACTH and corticosterone levels. Rats equipped with carotid cannula were used in this study. Blood samples $(400 \mu \mathrm{l})$ were drawn remotely at 20,10 , and 0 min (just before food presentation). Rats were then offered graham wafers for 10 min (shaded bar). Blood samples were collected at 5, 15, 30, and $60 \mathrm{~min}$ after food presentation. Plasma ACTH levels are expressed as picograms per milliliter and presented as mean \pm SEM (top). Plasma corticosterone levels are expressed as micrograms per $100 \mathrm{ml}$ and presented as mean \pm SEM (bottom).

including reinforcing drugs (Wise, 1996), food (Hernandez and Hoebel, 1988; Richardson and Gratton, 1996; Taber and Fibiger, 1997), or sex (Wenkstern et al., 1993). This led to the suggestions that catecholaminergic signals contribute to specific cognitive functions and/or arousal (Richardson and Gratton, 1996) or to processes related to attention and learning (Taber and Fibiger, 1997; Wickelgren, 1997). It is of interest to note that glucocorticoids too are secreted in response to stressful as well as rewarding events and have been suggested to represent a biological substrate of reward. According to this contention, glucocorticoids may play a role in counteracting the aversive effects of external threats or insults, allowing for better coping (Piazza and LeMoal, 1997). As in the case of brain dopamine circuits, we believe that the $\mathrm{CRH}$ system(s) may serve a much broader role than previously envisioned. Rather than evoking feelings of fear and anxiety, this system may serve to draw attention to biologically significant events (or cues) such as those associated with food availability and those posing physical threat.

The curious observation that an aversive event (such as acute restraint), as well as an apparently appetitive circumstance (such as meal ingestion), would both enhance the release of stress peptides ( $\mathrm{CRH}$ and $\mathrm{BN}$-like peptides) at the amygdala and stress hormones (ACTH and corticosterone) into general circulation may have an alternate explanation. It could be argued that at some central level, meal ingestion may be interpreted as a stressful event. Although, at first blush this may appear counterintuitive, observation of various species suggests that feeding-related activities can indeed be threatening to the organism, often requiring vigilance and/or aggression. For instance, acquisition of a meal by many carnivorous species may require hunting of the prey, a physically challenging and dangerous situation. Furthermore, during ingestion the organism may need to aggressively protect its food from others (e.g., a growling dog protecting his steak bone) or protect itself from attack during this vulnerable time (e.g., a bird at a feeder eating cautiously, vigilant about a potential attack from cohorts or birds of prey). Finally, the ingestion of a meal may signal imminent flooding of the system with nutrients and/or toxins that may threaten homeostasis. Thus, any or all of the events associated with feeding can potentially be deemed stressful. In the case of humans, the relatively plentiful conditions and structured social environment may have resulted in the brain-evolving effective mechanism(s) to suppress and/or modulate the perception of stress associated with food ingestion. According to such a model, it is conceivable that disruption of the mechanism(s) balancing the positive and negative (stressful) attributes of food ingestion may be associated with disorders affecting food intake such as anorexia nervosa, bulimia nervosa, depression, and obesity.

\section{REFERENCES}

Al-Damluji S, Iverson T, Thomas JM, Pendlebury DJ, Rees LH, Besser GM (1987) Food-induced cortisol secretion is mediated by central alpha-1 adrenoceptor modulation of pituitary ACTH secretion. Clin Endocrinol 26:629-636.

Bartanusz V, Jezova D, Bertini LT, Tilders FJ, Aubry J-M, Kiss JZ (1993) Stress-induced increase in vasopressin and corticotropinreleasing factor expression in hypophysiotrophic paraventricular neurons. Endocrinology 132:895-902.

Dallman MF, Akana SF, Strack AM, Hanson S, Sebastian RJ (1995) The neural network that regulates energy balance is responsive to glucocorticoids and insulin and also regulates HPA axis responsivity at sites proximal to CRF neurons. Ann NY Acad Sci 771:730-742.

Davis M, Rainnie D, Cassell M (1994) Neurotransmission in the rat amygdala related to fear and anxiety. Trends Neurosci 17:208-214.

Dunn AJ, Berridge CW (1990) Physiological and behavioral responses to corticotropin-releasing factor administration: is CRF a mediator of anxiety or stress responses? Brain Res Rev 15:71-100.

Follenius M, Brandenberger G, Hietter B (1982) Diurnal cortisol peaks and their relationships to meals. J Clin Endocrinol Metab 55:757-761.

Fukuda M, Ono T (1993) Amygdala-hypothalamic control of feeding behavior in monkey: single cell responses before and after reversible blockade of temporal cortex or amygdala projections. Behav Brain Res 55:233-241

Gaffan EA, Gaffan D, Harrison S (1988) Disconnection of the amygdala from visual association cortex impairs visual reward association in monkeys. J Neurosci 8:3144-3150.

Gibbs J (1985) Effect of bombesin on feeding behavior. Life Sci 37:147-153.

Gray TS (1991) Amygdala: role in autonomic and neuroendocrine responses to stress. In: Stress, neuropeptides and systemic Disease (McCubbin JA, Kauffman G, Nemeroff CB, eds), pp 37-53. New York: Academic.

Gray TS, Carney ME, Magnuson DJ (1989) Direct projections from the central amygdaloid nucleus to the hypothalamic paraventricular nucleus: possible role in stress-induced adrenocorticotropin release. Neuroendocrinology 50:433-446.

Heilig M, Koob GF, Ekman R, Britton KT (1994) Corticotropinreleasing factor and neuropeptide $\mathrm{Y}$ : role in emotional integration. Trends Neurosci 17:80-85.

Herman JP, Cullinan WE (1997) Neurocircuitry of stress: central control of the hypothalamo-pituitary-adrenocortical axis. Trends Neurosci 20:78-84.

Hernandez L, Hoebel BG (1988) Feeding and hypothalamic stimulation 
increase dopamine turnover in the accumbens. Physiol Behav 44:599-606.

Jones B, Mishkin M (1972) Limbic lesions and the problem of stimulusreinforcement associations. Exp Neurol 36:362-377.

Kalin NH, Takahashi LK, Chen F-TA (1994) Restraint stress increases corticotropin-releasing hormone mRNA content in the amygdala and paraventricular nucleus. Brain Res 656:182-186.

Karbonits M, Trainer PJ, Nelson ML, Howse I, Kopelman PG, Besser GM, Grossman AB, Svec F (1996) Differential stimulation of cortisol and dehydroepiandrosterone levels by food in obese and normal subjects: relation to body fat distribution. Clin Endocrinol 45:699-706.

Kent P, Anisman H, Merali Z (1998) Are bombesin-like peptides involved in the mediation of the stress response? Life Sci 62:103-114.

Kiss A, Palkovits M, Aguilera G (1996) Neural regulation of corticotropin releasing hormone $(\mathrm{CRH})$ and $\mathrm{CRH}$ receptor mRNA in the hypothalamic paraventricular nucleus in the rat. $\mathrm{J}$ Neuroendocrinol 8:103-112.

Kovács KJ, Sawchenko PE (1996) Sequence of stress-induced alterations in indices of synaptic and transcriptional activation in parvocellular neurosecretory neurons. J Neurosci 16:262-273.

Lee Y, Davis M (1997) Role of the hippocampus, the bed nucleus of the stria terminalis, and the amygdala in the excitatory effect of corticotropin-releasing hormone on the acoustic startle response. J Neurosci 17:6434-6446.

Maidment NT, Evans CJ (1991) Measurement of extracellular neuropeptides in the brain: microdialysis linked to solid-phase radioimmunoassays with sub-femptomole limits of detection. In: Microdialysis in the neurosciences (Robinson TE, Justice JB, eds), pp 275-303. Amsterdam: Elsevier.

Menzaghi F, Heinrichs SC, Pich EM, Weiss F, Koob GF (1993) The role of limbic and hypothalamic corticotropin-releasing factor in behavioral responses to stress. Ann NY Acad Sci 697:142-154.

Merali Z, Kateb CC (1993) Rapid alternations of hypothalamic and hippocampal bombesin-like peptide levels with feeding status. Am J Physiol 265:R420-R425.

Merali Z, Moody TW, Coy D (1993) Blockade of brain bombesin/GRP receptors increases food intake in satiated rats. Am $\mathrm{J}$ Physiol 264:R1031-R1034.

Merali Z, Plamondon H, Kent P, Banks K (1994) Corticotropinreleasing factor (CRF) antagonist blocks the autonomic, endocrine, ingestive and behavioral effects of central bombesin (BN). Soc Neurosci Abstr 528:1.

Moghaddam B, Bunney BS (1989) Ionic composition of microdialysis perfusing solution alters the pharmacological responsiveness and basal outflow of striatal dopamine. J Neurochem 53:652-654.

Moody TW, O’Donohue TL, Jacobowitz DM (1981) Biochemical localization and characterization of bombesin-like peptides in discrete regions of rat brain. Peptides 2:75-80.

Paxinos G, Watson C (1986) The brain in stereotaxic coordinates. New York: Academic.

Piazza PV, LeMoal M (1997) Glucocorticoids as a biological substrate of reward: physiological and pathophysiological implications. Brain Res Brain Res Rev 25:359-372.

Pich EM, Lorang M, Yeganeh M, Rodriguez de Fonseca F, Raber J, Koob GF, Weiss F (1995) Increase of extracellular corticotropinreleasing factor-like immunoreactivity levels in the amygdala of awake rats during restraint stress and ethanol withdrawal as measured by microdialysis. J Neurosci 15:5439-5447.

Plamondon H, Merali Z (1997) Regulation of ingestion by CRF and bombesin-like peptides: distinct meal-related peptide level changes. Am J Physiol 272:R268-R274.
Richardson NR, Gratton A (1996) Behavior-relevant changes in nucleus accumbens dopamine transmission elicited by food reinforcement: an electrochemical study in the rat. J Neurosci 16:8160-8169.

Rodríguez de Fonseca F, Carrera MRA, Navarro M, Koob GF, Weiss F (1997) Activation of corticotropin-releasing factor in the limbic system during cannabinoid withdrawal. Science 276:2050-2054.

Romero LM, Levine S, Sapolsky RM (1995) Adrenocorticotropin secretagog release: stimulation by frustration and paradoxically by reward presentation. Brain Res 676:151-156.

Salacinski PR, McLean C, Sykes JEC, Clement-Jones VV, Lowry PJ (1981) Iodination of proteins, and peptides using solid-phase oxidizing agent, 1,3,4,6-tetrachloro-3,6-diphenyl glycoluril (iodogen) radioiodine into proteins and peptides without damage. Anal Biochem 117:136-146.

Sawchenko PE, Brown ER, Chan RKW, Ericsson A, Li H-Y, Roland BL, Kovács KJ (1996) The paraventricular nucleus of the hypothalamus and the functional neuroanatomy of visceromotor responses to stress. Brain Res 107:201-222.

Schmidt ED, Binnekade R, Janszen AW, Tilders FJ (1996) Short stressor induced long-lasting increases of vasopressin stores in hypothalamic corticotropin-releasing hormone $(\mathrm{CRH})$ neurons in adult rats. J Neuroendocrinol 8:703-712.

Schwartz MW, Dallman MF, Woods SC (1995) Hypothalamic response to starvation: implications for the study of wasting disorders. Am J Physiol 269:R949-R957.

Shiraishi I, Honma K, Honma S, Hiroshige T (1984) Ethosecretogram: relation of behavior to plasma corticosterone in freely moving rats. Am J Physiol 247:R40-R45.

Spiegler BJ, Mishkin M (1981) Evidence for the sequential participation of inferior temporal cortex and amygdala in the acquisition of stimulusreward associations. Behav Brain Res 3:303-317.

Swiergiel AH, Takahashi LK, Kalin NH (1993) Attenuation of stressinduced behavior by antagonism of corticotropin-releasing factor receptors in the central amygdala in the rat. Brain Res 623:229-234.

Taber MT, Fibiger HC (1997) Activation of the mesocortical dopamine system by feeding: lack of selective response to stress. Neuroscience 77:295-298.

Tilders FJ, Schmidt ED, De Goeij DC (1993) Phenotypic plasticity of CRF neurons during stress. Ann NY Acad Sci 697:39-52.

Turnbull AV, Rivier C (1997) Corticotropin-releasing factor (CRF) and endocrine responses to stress: CRF receptors, binding protein, and related peptides. Proc Soc Exp Biol Med 215:1-10.

Vale W, Spiess J, Rivier C, Rivier J (1981) Characterization of a 41residue ovine hypothalamic peptide that stimulates secretion of corticotropin and $\beta$-endorphin. Science 213:1394-1397.

Vale W, Vaugham J, Yamamoto G, Bruhn T, Douglas T, Dalton D, Rivier C, Rivier J (1983) Assay of corticotropin releasing factor. Methods Enzymol 103:565-577.

Wada E, Way J, Lebacq-Verheyden AM, Battey JF (1990) Neuromedin $\mathrm{B}$ and gastrin-releasing peptide mRNAs are differentially distributed in the rat nervous system. J Neurosci 10:2917-2930.

Wenkstern D, Pfaus JG, Fibiger HC (1993) Dopamine transmission increases in the nucleus accumbens of male rats during their first exposure to sexually receptive female rats. Brain Res 618:41-46.

Wickelgren I (1997) Getting the brain's attention. Science 278:35-37.

Wise RA (1996) Neurobiology of addiction. Curr Opin Neurobiol 6:243-251.

Zola-Morgan S, Squire LR, Alvarez-Royo P, Clower RP (1991) Independence of memory functions and emotional behavior: separate contributions of the hippocampal formation and the amygdala. Hippocampus 1:207-220. 